\title{
A Comparison of Efficiency in Teacher Correction Strategies in Iranian EFL Learners' Speaking Improvement
}

\author{
Roya Keshavarz ${ }^{1} \&$ Amin Marzban ${ }^{1}$ \\ ${ }^{1}$ Department of Foreign Languages, Sepidan Branch, Islamic Azad University, Sepidan, Iran \\ Correspondence: Amin Marzban, Department of Foreign Languages, Sepidan Branch, Islamic Azad University, \\ Sepidan, Iran. E-mail: marzban@iausepidan.ac.ir
}

Received: August 28, 2016

Accepted: September 22, 2016 Online Published: November 23, 2016

doi:10.5539/ijel.v6n6p183

URL: http://dx.doi.org/10.5539/ijel.v6n6p183

\begin{abstract}
The present study was an attempt to investigate the effect two types of corrective feedback (i.e., recast and metalinguistic) in order to find out which one is more effective on EFL learners' speaking improvement and also to see if gender could play a role in the relative impact of the two types of corrective feedback on learners' speaking ability. To this end, 65 EFL learners of intermediate level in one of language institutes in Shiraz, Iran were selected and divided into three groups including two experimental groups and one control. The instruments used to collect the data included IELTS test as the pre and post tests and Oxford Placement Test (OPT) in order to obtain the homogeneity in participants' English proficiency. The collected data were codified and entered into SPSS Software (Version 22) and were analysed using descriptive statistics, t-test, and Tukey test. The results indicated that although applying these two types of corrective feedback could have made improvement in EFL learners' speaking ability, there was not observed any significant difference between impacts of recast and metalinguistic on EFL learners' production. The test results also indicated that there was not any significant difference regarding gender within the three groups. This homogeneity further shows that in this study, the gender variable did not have any effect on the role of corrective feedback and it can be concluded that the observed difference between metalinguistic group, recast group, and control group is just the result of the provided corrective feedback type which has acted as the intervening variable and the moderator variable such as gender did not prove to have any effect in the outcome of this study. The findings can contribute to syllabus design and teaching methodology areas.
\end{abstract}

\section{Introduction}

Undoubtedly, learners of second language commit some errors and by correcting these errors in some special ways, the process of learning another language is going to be complete. When learners produce incorrect utterances, it is important that teachers know how to correct them. Therefore, the way through which learners' errors are corrected is quite important in process of teaching and learning English as Second Language (ESL) or English as a Foreign Language (EFL). In fact, without correcting errors, the process of learning and teaching another language would remain incomplete and errors would be fossilized in the learners' mind.

An important issue that has attracted much attention recently is how the learners' errors could be corrected and which techniques should be applied for correcting EFL and ESL learners' errors. Numerous studies have been done over this issue and regarding learners' age, proficiency, nationality, preferred and the other factors; the results of such pieces of research are different but there appears to be a common agreement among researchers that corrective feedback is a vital factor in every language learning context and all such studies have tried to show the importance of corrective feedback. In Some traditional approaches, pronunciation as an aspect of speaking ability was not accounted an effective factor (e.g., Purcell \& Suter, 1980) but in recent methodologies, pronunciation has been considered an essential component of a language (Pennington, 1994). In addition, Ferris (1999) "suggested that attention be given to investigating which methods, techniques, or approaches to error correction lead to short-term or long-term improvement and whether students make better development in observing certain types of errors than others".

Lyster (2007) classified teacher corrective feedback into two broad categories: reformulations and prompts. In reformulations, errors that are made by learners would be rephrased in correct forms. However, in prompts, teachers as directly or indirectly push and ask learners to correct themselves and produce the correct form. Ellis 
(2009) introduces these two types of feedback as input providing and output prompting strategies.

Since the aim of learning a language is significantly done to enable learners to produce correct output, corrective feedback has got a special position in teaching and learning English language process specially speaking and pronunciation. Several experts believe that speaking ability is the main yardstick for evaluating learner's success in process of learning other languages; for instance, Marks (2006) points out that pronunciation is a main and basic factor for using language in the communicative competence.

When it is claimed that a learner is successful commonly refers to the fact that he/she can speak fluently and is accurate to an acceptable rate. As speaking is considered an output, so it is completely clear that the issue of pronunciation is quite important in acquisition of foreign or second language and vocabulary of the target language must be pronounced correctly. "Once, in the era of behaviorism and audiolingualism, it was believed that errors should be eradicated at any level because language learning was considered as a kind of habit formation and by committing errors, one could form some bad habits in his/her behaviour" (Soleimani et al., 2014).

Error production can be considered as a successful step towards progress for learners and teachers, if errors are immediately corrected by the teacher. Furthermore, error production can be a danger for speaking and pronunciation if the error would not be corrected spontaneously, it would be fossilized in learner's minds and turns to an incorrect habitual pronunciation for the learner. Here, the importance of teacher's corrective feedback is better comprehended.

The type of teacher's corrective feedback through which errors of pronunciation are corrected is important as well. "Corrective feedback must be taken into account, since frequent corrections may lower learners' self-confidence and decrease motivation or even result in disappointment, frustration and ultimately, reluctance and rejection" (Murphy, 1991). During a course, teachers don't have enough time to try a variety of teacher corrective feedback types. If they do so, they can't achieve the aim of teaching and gain the appropriate feedback as a result of doing error correction. In the present study, the researcher will investigate two types of corrective feedback for EFL learners' pronunciation. This research is an attempt to investigate the impact of two types of corrective feedback on learners' pronunciation and also finding out if there is any difference between two types of corrective feedback (meta-linguistic and recast) and also discover if participants' gender would be effective on the types of corrective feedback.

The importance of this study thus lies in comparing two types of corrective feedback (i.e., meta-linguistic and recast) and investigating the effect of both types on speaking improvement. Accordingly, the more effective corrective feedback type will be recognized. Teachers could apply this to their classes in order to get better results and help learners produce words with correct pronunciation and sound speaking ability.

The other important aspect of this study is to search about correcting pronunciation. The Correct pronunciation is an important factor that can help and motivate learners to have communication with native speakers and also comprehend them better. This study by recognizing an effective corrective feedback type could make a salient improvement for EFL learners.

\section{Literature Review}

\subsection{Theoretical Background on Corrective Feedback}

To ensure the effectiveness of corrective feedback; some factors are quite important such as: timing, amount, mode, and audience. Also, clearness of corrective feedback should be as much that learners could comprehend. It means the teacher should be careful during error correction and application of the right kind of corrective feedback. The learners should participate in the process of pronunciation correction and should not be distracted. Miremadi (2004) says that a person's pronunciation when they speak has a significant effect on their identity. When we speak about pronunciation, it does not mean that a learner should have native-like accent, rather it means learner must learn to pronounce correctly and speak in a way that be comprehensible to hearer.

\subsection{Empirical Background on Corrective Feedback}

Lochtman (2002) in a related study tried to investigate different corrective feedback types as the frequency and distribution considering learners' uptake. Function of her research was based on oral corrective feedback in ESL context. According to her research, the most popular types of teacher corrective feedback were recasts and elicitations types. In addition, the results showed that recasts and explicit types were the least effective types of corrective feedback, and metalinguistic feedback and elicitations were the most effective types considering learners' uptake. 
Lyster (1997) also presented a study in which they classified various types of corrective feedback used by teachers in response to learner errors. They conducted a study in French immersion classrooms and found that recasts were used more frequently (55\%) than other types of feedback such as explicit (7\%) correction, metalinguistic feedback (8\%), clarification Requests (11\%), elicitation and repetition (5\%), which was used less frequently. Although recasts have had the high frequency of occurrence, they have the least amount of uptake (31\%) while it is showed $80 \%$ of learners' uptake belongs to the other feedback types. It was also found that the rate of uptake that is elicited by recasts is lower and only seen in $40 \%$ of cases; the students correct their output by recasts. While other types of feedback such as clarification requests, elicitation, repetition, and metalinguistic clues, resulted in successful uptake elicitation over $70 \%$ of the times they were used. In support of this result, Ellis et al. (2001) indicated that the high rate of uptake elicitation in recasts is $71.6 \%$. The rate in other types of corrective feedback was even higher, ranging from $80 \%$ to $100 \%$.

According to the above percentage distribution, recast (55\%) is more popular among teachers and most of them are eager to use this corrective feedback type. But recasts have the lowest rate of repair and uptake .A more important to mention is that in recasts explicit correction, peer- and self-repair cannot be applicable although these two are effective techniques to error correction. Opposite to that, elicitation, metalinguistic clues, clarification request, and the repetition of error could be applicable for peer- and self -repair and teachers can elicit the correct form. These types also have higher rates of uptake. These four teacher correction feedback types are also called negotiation of forms that are useful for SLA in two ways: first, they place learners in a situation, where they could use and apply their target language knowledge and in this way the correct form would be focalized in their memory (e.g., Hulstijn, 1990; Nobuyoshi \& Ellis, 1993; Towell, Awkins, \& Bazergui, 1996). Second, by drawing learners' attention to form during communicative interaction, the learners' attention would be drawn in some ways that enable learners to modify the incorrect output and test new hypotheses about the target language (e.g., Pica, 1988; Swain, 1993, 1995).

Theoretical arguments have been advanced for teacher correction types. Rahimi \& Sobhani (2015) investigated the relationship between types and distribution of corrective feedback and their effects on learners' uptake in Iranian adult EFL classrooms. In the study, it was showed that the more frequent teacher correction type which was received by the learners in all proficiency levels, is the recast type and the elicitation and request for clarification were more useful to learners' uptake.

Lyster (2004) in a study claimed that the effectiveness of metalinguistic feedback is more than recasts. Lyster justifies this claim by bringing the reason that the Metalinguistic feedback gives explicit information about the target structure; therefore, in learners view it seemed to be more facilitative. However, this perspective is proven in all studies which have worked on this subject. Kim \& Mathes (2001), for example, in their study reported that they never observed any statistically significant differences in the scores of the explicit and implicit groups.

Surakka (2007) investigated the frequency and effectiveness of various corrective feedback types in Finnish EFL classrooms. She found out that although recast is provided as the most frequent type of corrective feedback by teachers, recasts and explicit correction were not the most effective strategies regarding learners' uptake in this study, but other types of corrective feedback such as elicitation and metalinguistic feedback were more successful strategies for learner's uptake.

In a different project done by Chen (2011) there was made a comparison between oral recasts and elicitations. The first type was considered implicit and the second was considered explicit feedback to evaluate their effects on the oral prosody. The operation of experimental group was compared with the control group in which there was not applied any corrective feedback in classroom practices. Results have shown that self-repairs or prompts were most effective for L2 learners to improve their prosodic accuracy. In this study, it seemed that recasts and elicitations have some effects on learning the targeted prosodic forms but the results recommended that learners' reaction regarding different corrective feedback types would be different and findings proved that there is a direct relation between corrective feedback type and learners' language proficiency.

Lyster \& Saito (2010) in their meta-analysis looked into the pedagogical effectiveness of oral corrective feedback on target language development. They found out that corrective feedback has salient effect on the process of language learning. They concluded that the logical results for effectiveness of prompts are larger than recasts. They also found that corrective feedback types are more influential on younger learners rather than the older ones. The reason might be relevant to more pedagogical flexibility of younger learners in learning materials.

Ruili (2011) has carried out a study on corrective feedback with various perspectives. Chu tried to find out if there was a positive effect on improving oral English accuracy. Moreover, two types of corrective feedback were 
investigated to distinguished which type was more effective on English accuracy and if corrective feedback can improve oral English accuracy, the extent of improving will be the same for the high medium and low group of students.

Kennedy (2010) investigated the effect of teacher's corrective feedback on two different proficiency levels. Fifteen child ESL learners participated in two different proficiency levels. The results of the study showed that each proficiency group had different types of errors. The low proficiency group's error production was more about content while the high proficiency group's error was more about form. Regarding teacher feedback, the teacher believed that the high proficiency group could do self-correction and the low proficiency group needed more help; therefore, the teacher used corrective feedback type for the low group, which gives the correct form. The study resulted that the high proficiency group had a higher rate of uptake and repair compared with the low proficiency group. Besides, the high proficiency level group might have more linguistic knowledge that enables them to improve their utterances.

Ammar (2008) in a study investigated the different effects of recast and prompts for third person possessive determiners among Francophone learners. The participants received corrective feedback while they were doing some communicative activities. The results indicated that prompts were more effective than recasts in the learners' accomplishment of third person possessive determiners.

Tomczyk (2013) tried to make a comparison between teachers' perceptions and students' perceptions about oral errors and their corrective feedback. She considers corrective feedback as an inseparable part of language acquisition. The findings indicate that there are differences and similarities in view of the respondents of the two groups in comparison with real situation in the class that showed learners' error correction is not a simple issue and needs to be more investigated.

Qiao (2013) investigated the effect of implicit feedback (i.e., recasts) and explicit feedback (i.e., metalinguistic) on American students' acquisition of Chinese directional verb compounds, that it is respective to expressing motion events in Chinese. There were three Chinese groups at intermediate-level of English. The task which was presented among groups was picture description. One group received implicit feedback in order to correct their errors, another received explicit feedback, and the control group received no feedback. A pre-test, an immediate post-test, and a delayed post-test were administered. He observed improvement in both experimental groups' performance on the intermediate post-test, while this result was not observed in control group. As well, the improvement of recast group was stable in the delayed post-test, whereas the improvement decreased in metalinguistic group on the delayed post-test. The results showed a probable short-term positive effect of the two types.

\section{Method}

\subsection{Introduction}

As mentioned earlier, the purpose of the present study was to make a comparison between two teacher correction strategies (i.e., recast and metalinguistic) in Iranian EFL speaking improvement and also to investigate if gender and age play any roles in application of such types of corrective feedback. The method of this study is thus basically quantitative and addresses the following research questions.

1) Which type of teacher correction (i.e., recast and metalinguistic) is more effective in improving learners' speaking?

2) Does gender make a significant difference in the application of the two types of corrective feedback?

\subsection{Participants}

The sample included 65 male and female learners selected from Nokhbegan institute in Shiraz, Iran. The age of the learners ranged from 15 to 25 (Mage: 18.33). They were selected from the existing population of 95 English learners. They were divided into one control group and two experimental groups placed in three different classes. Class A with twenty students and class B with twenty two and class C with twenty three students.

The quick OPT test version two was used in order to run the placement. In fact, the aim of administrating OPT test was to homogenize the participants into the intermediate level. The simple random sampling technique (SRS) was used for selecting participants of this study. According to this sample, all participants had the same chance to be included in the sampling frame.

\subsection{Instruments}

Multiple data collection instruments were used to obtain comprehensive and useful data and to increase the validity of the findings. The data were collected from IELTS test as pre and post-tests. 


\subsubsection{The Oxford Placement Test (OPT)}

The Oxford Placement Test reports students' status on a continuous numerical scale. It is a very reliable tool for placing students in courses at the optimal level. This test is validated by Oxford University. If a student were reported to have a score of 61 , it means that they are judged to have reached a very low level B2. A score of 71 would indicate a student comfortably at level B2.

\subsubsection{Pre and Post Tests}

Pre and post tests were administered to enable the researcher to compare learners' scores after treatment sections and achieve the goal of this research that is comparing the effects of two types of corrective feedback and also checking if there was any significant difference between these two types.

The IELTS speaking module was used as the pre-test in order to evaluate participant's prior knowledge. A certified IELTS examiner was invited to run the IELTS speaking interview. The test was interactive and close to real-life context. The time duration for test was 11-14 minutes with three phases: the participants answered questions about themselves and their family. In part two, they talked about a topic. In part three, participants had a longer discussion on the topic. The participants' scores on the IELTS test were measured regarding how accurate participants' pronunciation was. Features such as basic word pronunciation, linked speech sounds, correct sentence stress, and correct use of intonation (rising and falling) were focused by examiner to measure participants' English proficiency in speaking.

The IELTS speaking module as the post-test was repeated. This time, the aim was to see possible changes in participant's scores after eight treatment sessions and compare them with pre-test scores

\section{Findings}

\subsection{Descriptive Statistics}

Descriptive statistics for age distribution in three groups was presented as follows:

Table 1. Age distribution in class A, B, C

\begin{tabular}{|c|c|c|c|}
\hline Group & Age & Frequency & Valid Percent \\
\hline \multirow{12}{*}{ Class A } & 15 & 2 & 10.0 \\
\hline & 16 & 2 & 10.0 \\
\hline & 17 & 2 & 10.0 \\
\hline & 18 & 2 & 10.0 \\
\hline & 19 & 2 & 10.0 \\
\hline & 20 & 2 & 10.0 \\
\hline & 21 & 2 & 10.0 \\
\hline & 22 & 2 & 10.0 \\
\hline & 23 & 1 & 5.0 \\
\hline & 24 & 1 & 5.0 \\
\hline & 25 & 2 & 10.0 \\
\hline & Total & 20 & 100.0 \\
\hline \multirow[t]{11}{*}{ Class B } & 15 & 2 & 9.1 \\
\hline & 16 & 2 & 9.1 \\
\hline & 17 & 3 & 13.6 \\
\hline & 18 & 2 & 9.1 \\
\hline & 19 & 2 & 9.1 \\
\hline & 20 & 3 & 13.6 \\
\hline & 22 & 2 & 9.1 \\
\hline & 23 & 2 & 9.1 \\
\hline & 24 & 2 & 9.1 \\
\hline & 25 & 2 & 9.1 \\
\hline & Total & 22 & 100.0 \\
\hline \multirow[t]{11}{*}{ Class $\mathrm{C}$} & 15 & 1 & 4.3 \\
\hline & 16 & 1 & 4.3 \\
\hline & 17 & 2 & 8.7 \\
\hline & 18 & 3 & 13.0 \\
\hline & 19 & 4 & 17.4 \\
\hline & 20 & 2 & 8.7 \\
\hline & 22 & 2 & 8.7 \\
\hline & 23 & 3 & 13.0 \\
\hline & 24 & 2 & 8.7 \\
\hline & 25 & 3 & 13.0 \\
\hline & Total & 23 & 100.0 \\
\hline
\end{tabular}


The frequency and frequency percent of studied sample according to age distribution in three classes are shown in the table above.

Descriptive statistics for gender distribution in three groups was presented as follows:

Table 2. Gender distribution in class A, B, C

\begin{tabular}{llll}
\hline Group & Gender & Frequency & Valid Percent \\
\hline Class A & Male & 9 & 45.0 \\
& Female & 11 & 55.0 \\
& Total & 20 & 100.0 \\
\hline Class B & Male & 11 & 50.0 \\
& Female & 11 & 50.0 \\
& Total & 22 & 100.0 \\
\hline Class C & Male & 12 & 52.2 \\
& Female & 11 & 47.8 \\
& Total & 23 & 100.0 \\
\hline
\end{tabular}

As you can see in the above table, the frequency and frequency percentage of studied sample according to gender distribution in three classes (A, B, C) was calculated.

The mean and SD of participants' scores was determined separately in all three classes.

Table 3. The mean and SD of participants' scores in three classes (A, B, C).

\begin{tabular}{llll}
\hline Group & & Pre test & Post test \\
\hline Class A & Mean & 4.1500 & 5.3250 \\
& Std. Deviation & 0.87509 & 1.16161 \\
\hline Class B & Mean & 4.1136 & 5.6818 \\
& Std. Deviation & 0.87194 & 1.11852 \\
\hline Class C & Mean & 4.2174 & 4.1304 \\
& Std. Deviation & 0.83701 & 0.99107 \\
\hline
\end{tabular}

The above table shows the mean and SD of participants' scores according to their classes in pre and post-tests. Regarding this table, before presenting corrective feedback types, there was not seen any differences among the participants' scores of each group in pre-test. Nonetheless, the participants' scores in post- test shows a difference among scores of the two experimental groups (A\&B) and control group (C) but it cannot be said that this difference is significant and applying corrective feedback type has been effective.

The following table indicates the mean and SD of participants' scores according to classes and participants' gender.

Table 4. The mean and SD of participants' scores according to classes and participants' gender

\begin{tabular}{|c|c|c|c|c|c|}
\hline Group & Gender & & $\mathrm{N}$ & Mean & Std. Deviation \\
\hline \multirow[t]{6}{*}{ Class A } & Male & pretest & 9 & 4.4444 & .98249 \\
\hline & & Post-test & 9 & 5.6667 & 1.25000 \\
\hline & & Valid N (listwise) & 9 & & \\
\hline & Female & pretest & 11 & 3.9091 & .73547 \\
\hline & & Post-test & 11 & 5.0455 & 1.05959 \\
\hline & & Valid N (listwise) & 11 & & \\
\hline \multirow[t]{6}{*}{ Class B } & Male & pretest & 11 & 4.3182 & .90202 \\
\hline & & Post-test & 11 & 6.0909 & 1.06813 \\
\hline & & Valid N (listwise) & 11 & & \\
\hline & Female & pretest & 11 & 3.9091 & .83121 \\
\hline & & Post-test & 11 & 5.2727 & 1.05744 \\
\hline & & Valid N (listwise) & 11 & & \\
\hline \multirow[t]{3}{*}{ Class C } & Male & pretest & 12 & 4.2083 & .78214 \\
\hline & & Post-test & 12 & 4.1667 & 1.13485 \\
\hline & & Valid N (listwise) & 12 & & \\
\hline
\end{tabular}




\begin{tabular}{lllll}
\hline Female & Pre-test & 11 & 4.2273 & .93176 \\
& Post-test & 11 & 4.0909 & .86076 \\
& Valid N (listwise) & 11 & & \\
\hline
\end{tabular}

In the above table, the mean and SD of participants' scores have been shown according to classes and participants' gender in pre-test and post-test. As seen in the above table, there is no difference in pre-test scores of male participants in each class. But this difference is remarkable between the scores of experimental groups (A\&B) in comparison with control group (C).This differences also holds true about female participants.

The following figure shows participants' scores distribution based on class and gender.

\subsection{Inferential Statistics}

\subsubsection{Determining Variance Homogeneity}

The following table investigates the homogeneity of data.

Table 5. Levene test to investigate homogeneity of data

\begin{tabular}{ll}
\hline Levene's Test of Equality of Variances & \\
\hline $\mathrm{F}$ & Sig. \\
.006 & .994 \\
\hline
\end{tabular}

In order to investigate data homogeneity, the Levene test was applied. In investigation of homogeneity of the whole test, $\mathrm{F}=0 / 006$ had significant level of 0/994 that was upper than the acceptable level for rejecting the null hypothesis. Therefore, there is no significant difference among the variance of groups and the assumption of variance homogeneity is stable.

Table 6. The result of covariance analysis

\begin{tabular}{llllclcc}
\hline Source & $\begin{array}{l}\text { Dependent } \\
\text { Variable }\end{array}$ & Sum of Squares & df & Mean Square & F & Sig. & Value \\
\hline Group & Post test & 37.614 & 2 & 18.807 & 11.091 & 0.000 & 0.964 \\
\hline
\end{tabular}

The above table shows the effect of intervention of corrective feedback types on the dependent variable or post-test in three groups. Regarding the significant level of $F$ that is less than $0 / 001$ we can claim that applying corrective feedback types to tackle pronunciation error correction is effective.

Table 7. ANOVA test for investigating the difference among participants' scores of each class in pre and post-tests

\begin{tabular}{lllllll}
\hline & & Sum of Squares & df & Mean Square & F & Sig. \\
\hline \multirow{3}{*}{ Pre- test } & Between Groups & 0.125 & 2 & 0.062 & 0.084 & 0.919 \\
& Within Groups & 45.929 & 62 & .741 & & \\
& Total & 46.054 & 64 & & & \\
\hline \multirow{3}{*}{ Post- test } & Between Groups & 29.696 & 2 & 14.848 & 12.522 & 0.000 \\
& Within Groups & 73.519 & 62 & 1.186 & & \\
& Total & 103.215 & 64 & & & \\
\hline
\end{tabular}

As you notice in the above table, there is no significant differences among the studied groups (one control group and two experimental groups) in pre-test but regarding significant value of $\mathrm{F}$ in post-test at level of 0.01 , it can be said that presenting corrective feedback types as a method of rectifying pronunciation error has been effective. Nevertheless this table does not determine which corrective feedback type has been more effective.

As there was observed a significant difference among all three groups in post-test, therefore, in order to recognize which type is more effective, the researcher made use of the Tukey test. 
Table 8. (Tukey HSD) In order to investigate about participants' scores before intervention of corrective feedback types

\begin{tabular}{lll}
\hline group & $\mathrm{N}$ & $\begin{array}{l}\text { Subset for alpha }=0.05 \\
1\end{array}$ \\
\hline Class B & 22 & 4.1136 \\
Class A & 20 & 4.1500 \\
Class C & 23 & 4.2174 \\
Sig. & & 0.917 \\
\hline
\end{tabular}

As it is shown in the ANOVA analysis table, there was not any significant difference among the participants' scores of three groups in pre-test.

To run the Tukey test, the participants' scores in all three groups have been located in one class. The following diagram shows this issue.

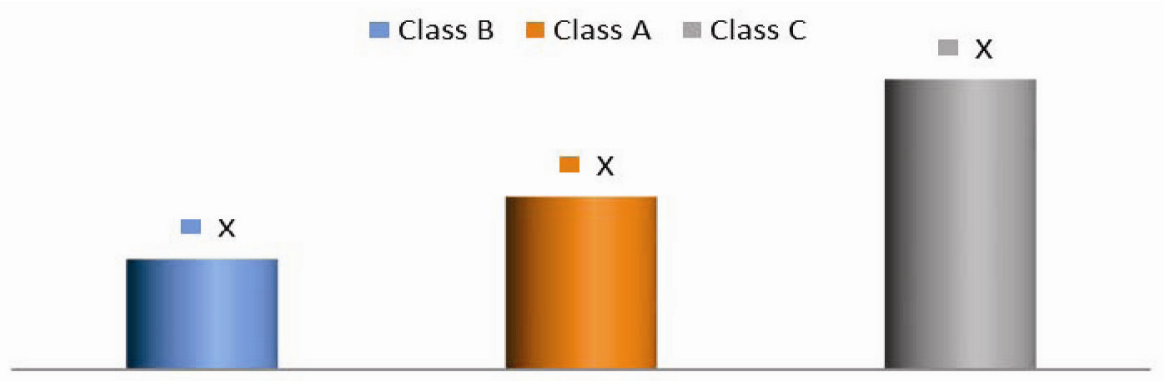

Figure 1. Ranking of participants' scores under study in pre-test

The X mark on the columns shows that the participants' scores in all three classes belong to one class.

The following table shows investigation about the differences among the participants' scores of three groups in post-test.

Table 9. Tukey HSD to investigate the participants' scores after intervention of corrective feedback types

\begin{tabular}{|c|c|c|c|}
\hline \multirow{2}{*}{ Group } & \multirow{2}{*}{$\mathrm{N}$} & \multicolumn{2}{|c|}{ Subset for alpha $=0.0$} \\
\hline & & 1 & 2 \\
\hline Class $\mathrm{C}$ & 23 & 4.1304 & \\
\hline Class A & 20 & & 5.3250 \\
\hline Class B & 22 & & 5.6818 \\
\hline Sig. & & 1.000 & 0.532 \\
\hline
\end{tabular}

As you notice in the ANOVA analysis table, we observed a significant difference among the participants' scores of three groups in post-test. According to Tukey test, the participants' scores of the two experimental groups belong to one class while participants' scores in control group belong to another class. This means that applying the corrective feedback types were effective but the difference between them is not significant enough that can be judged which corrective feedback type was more effective.

The following diagram refers to this issue. 


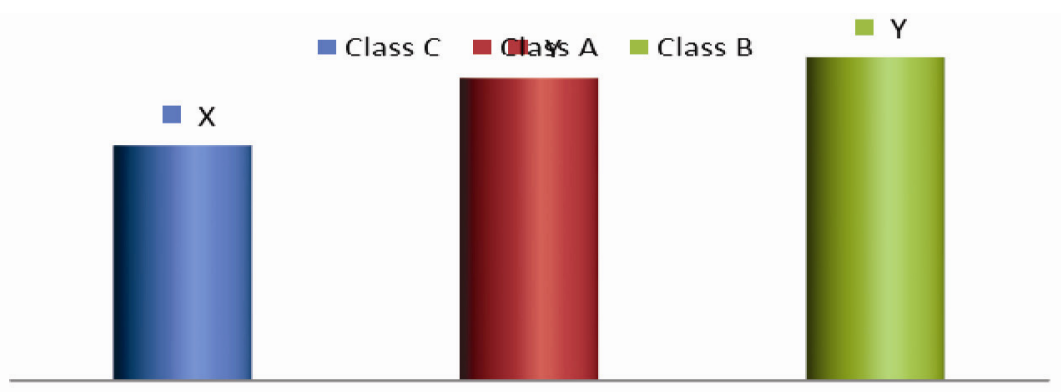

Figure 2. Ranking of participants' scores under study in post-test

The X and Y marks show that the participants' scores of experimental groups are identical but they are different from the scores in control groups.

The following table indicates the effect of applying corrective feedback type on participants' pronunciation error based on gender variable of studied groups.

Table 10. Paired samples t-test in to investigate the difference between scores of pre and post-tests in studied groups based on gender

\begin{tabular}{lllllll}
\hline Group & Gender & Mean & Std. Deviation & $\mathrm{t}$ & $\mathrm{df}$ & Sig. (2-tailed) \\
\hline Class A & Male & -1.222 & 0.50690 & -7.234 & 8 & 0.000 \\
& Female & -1.136 & 0.71031 & -5.306 & 10 & 0.000 \\
\hline \multirow{2}{*}{ Class B } & Male & -1.772 & 1.16969 & -5.027 & 10 & 0.001 \\
& Female & -1.363 & 0.83937 & -5.388 & 10 & 0.000 \\
\hline Class C & Male & 0.0416 & 0.58225 & 0.248 & 11 & 0.809 \\
& Female & 0.1363 & 0.23355 & 1.936 & 10 & 0.082 \\
\hline
\end{tabular}

As it is shown in the table, class $\mathrm{C}$ is considered control group and according to gender of participants, the $\mathrm{t}$ value at 0.05 levels, has not been significant. This means that, according to gender variable there is no significant difference between participants' scores in pre and post- tests. On the other hand, according to corrective feedback types, the $t$ value $s$ in classes $A$ and $B$ has been significant separately. This implies that in these two classes; there is a significant difference between the mean of participants' scores in pre-test and post-test. Therefore, presenting two corrective feedback types has been effective on the pronunciation error correction of both males and females.

In order to investigate about the difference between the effect of the two types of corrective feedback on males and females in classes $\mathrm{A}$ and $\mathrm{B}$, the independent t-test was used.

Table 11. Independent t-test in order to investigate the effect of gender on corrective feedback types in studied groups

\begin{tabular}{lllllll}
\hline \multirow{2}{*}{ Group } & \multicolumn{2}{l}{$\begin{array}{l}\text { Levene's Test for Equality } \\
\text { of Variances }\end{array}$} & \multicolumn{5}{l}{ t-test for Equality of Means } \\
\hline & F & Sig. & t & df & Sig. (2-tailed) & Mean Difference \\
\hline Class A & 0.412 & 0.529 & 1.204 & 18 & 0.244 & 0.62121 \\
Class B & 0.063 & 0.804 & 1.805 & 20 & 0.086 & 0.81818 \\
Class C & 2.326 & 0.142 & 0.179 & 21 & 0.860 & 0.07576 \\
\hline
\end{tabular}

The table above investigates about the effect of participants' gender on corrective feedback types in studied groups. Since there is no significance for F value in Levene test, we can say that in terms of gender, the participant classification is homogenous. Since the value of $t$ at level of 0.05 has not been considered significant, it can be said that there is no significant difference between the effects of the two types of corrective feedback on participants' gender. 


\section{Discussion and Conclusion}

It seems that both question of this study were answered based on the results of the statistical analysis. According to results obtained via ANOVA, we observed insignificant difference between the two types of corrective feedback types (i.e., recast \& meta-linguistic) on participants' error pronunciation that cannot be considered statistically while significant differences were found between the students who participated in classes, where applied two teacher correction feedback types (recast \& meta-linguistic) and those who were considered control group (class C). In line with this study, findings of some studies revealed that recast, elicitation and metalinguistic feedback types are the most commonly used approaches. According to the result of that study in regarding for the mentioned hypothesis, it has been maintained that recast feedback type is the most common approach that is applied by most of teachers in order to teach vocabulary and pronunciation. But metalinguistic is predominantly used for teaching grammar.

Regarding the second question of this study, the test results show that there is no significant difference among three groups in terms of the effect of corrective feedback types on participants' gender. In a study launched by Rezaei \& Derakhshan (2011), the effect of two types of corrective feedback (i.e., recast and metalinguistic) on task-based grammar instruction was investigated. Additionally In this study the findings revealed that both these two corrective feedback types are effective in task-based grammar instruction but the one which is more effective is metalinguistic feedback type. Achieving such findings might be the explicit nature of metalinguistic.

Gholizade (2013) also investigated the effect of recast and meta-linguistic on accuracy, fluency and complexity of speaking performance of males and females. The findings showed that metalinguistic is more effective in speaking accuracy, fluency and complexity. In this study, there was not any significant difference between male and female, similarly to the present study. Achieving this result might be the result of the number of participants; namely, 120 participants attended in her study. The number of participants made a significant mean difference between groups. In the present study, just 65 participants took part and because of this it is not strange that the mean difference between metalinguistic group and recast group is insignificant.

Abedi et al. (2015) in a study compared the effect of recast and direct corrective feedback types on learners' pronunciation. That study brought about different results. These two types were presented on two groups. When the collected data were analyzed, in contrast to this study, the findings showed that recast had a significant effect on the learners' pronunciation and the improvement was seen more in group which received recast type. In this study, recast correction outperformed the other types because there are some weak points attached to using direct corrective feedback. Terrell (1985) studied about teacher's direct feedback and came to three reasons to avoid correcting students' error directly:

It does not lead to more correct language usage in the future,

It may result in negative affective feelings that interfere with learning,

It will probably cause students to focus their attention on language rather than meaning.

Similar to the methodology of present study, a research was done by Zhuo (2010) which focused on the relative effects of explicit and implicit recasts on the acquisition of English language. The participants of this study were divided into three groups. One group received explicit recast, the other group received implicit type and the third group which was considered control group didn't receive any corrective feedback. The findings of this study showed that all three groups had significant improvement overtime. But the improvement was seen more among explicit recast group.

Results of some other studies in line with the current study, revealed that the corrective feedback strategies can make improvement for EFL learners based on the type of produced error and also it was found that explicit types, which metalinguistic type is deemed one of them has a higher impact on language learning and thereby helps to enhance the process of learning better. The justification lies in the fact that EFL learners pay more attention to explicit corrective feedback types.

\section{References}

Abedi, M., Karimi, L., \& Gholami, M. A. (2015). Comparing the Effects of Recast vs. Direct Feedback on EFL Students' Pronunciation Accuracy. International Journal of Educational Investigations, 2(3), 159-169.

Abuelnour, E. H. B., \& Ibrahim Holi Ali, H. (2013). Rationalizing Oral Corrective Feedback in Sudanese EFL Classrooms. International Journal of Applied Linguistics \& English Literature, 3(3).

Ammar, A. (2008). Prompts and recasts: Differential effects on second language morphosyntax. Language Teaching Research, 12, 183-210. http://dx.doi.org/10.1177/1362168807086287 
Chen, C. (2011). Effects of Corrective Feedback in the Prosodic Development of L2 Learners. The Asian Conference on Language Learning (pp. 48-60).

Ellis, R. (2009a). Corrective feedback and teacher development. L2 Journal, 1(1), 3-18.

Fraser, H. (1999). ESL Pronunciation Teaching: Could it be More Effective? Retrieved from http://www.une.edu.au/arts/ALS/als.htm

Gholizade, R. (2013). The Investigation of Differential Effects of Recast and Metalinguistic Feedback on Accuracy, Fluency, and Complexity of Speaking Performance of Male and Female EFL Learners. Journal of Novel Applied Sciences, 2(9), 417-428.

Hulstijn, J. (1990). A comparison between the information-processing and the analysis/control approaches to language learning. Applied Linguistics, 11, 30-45. http://dx.doi.org/10.1093/applin/11.1.30

Kennedy, S. (2010). Corrective feedback for learners of varied proficiency levels: A teacher's choices. TESL Canada Journal, 27(2), 31-50. http://dx.doi.org/10.18806/tesl.v27i2.1054

Kim, H., \& Mathes, G. (2001). Explicit vs. implicit corrective feedback. The Korea TESOL Journal, 4, 1-15.

Lochtman, K. (2002). Oral corrective feedback in the foreign language classroom: how it affects interaction in analytic foreign language teaching. International Journal of Educational Research, 37, 271-283. http://dx.doi.org/10.1016/S0883-0355(03)00005-3

Lyster, R. (2004). Different effects of prompts and effects in form-focused instruction. Studies in Second Language Acquisition, 26, 399-432. http://dx.doi.org/10.1017/S0272263104263021

Lyster, R., \& Ranta, L. (1997). Corrective feedback and learner uptake: Negotiation of form in communicative $\begin{array}{lllll}\text { classrooms. Studies in Second Language Acquisition, } & \text { 19, }\end{array}$ http://dx.doi.org/10.1017/s0272263197001034

Lyster, R., \& Satio, K. (2010). Oral feedback in classroom SLA: A meta-analysis. Studies in Second language Acquisition, 32, 265-302. http://dx.doi.org/10.1017/S0272263109990520

Marks, J. (2006). Pronunciation in Course books Again. Speak Out, 36, 33-35.

Miremadi, S. A. (2004). A textbook on teaching proper pronunciation. Tehran: Mahdavi Publication.

Murphy, J. M. (1991). Oral Communication in TESOL: Integrating Speaking, Listening, and Pronunciation. TESOL Quarterly, 25(1), 51-75. http://dx.doi.org/10.2307/3587028

Nobuyoshi, J., \& Ellis, R. (1993). Focused communication tasks and second language Acquisition. ELT Journal, 47, 203-210. http://dx.doi.org/10.1093/elt/47.3.203

Pennington, M. (1994). Recent research in L2 phonology: Implications for practice. In J. Morley (Ed.), Pronunciation Pedagogy and Theory: New Views, New Directions (pp. 92-108). Alexandria, VA: Teachers of English to Speakers of Other Languages (EDRS No. ED 388 061).

Purcell, E., \& Suter, R. (1980). Predictors of pronunciation accuracy: A re-examination. Language Learning, 30, 271-287.

Pica, T. (1988). Interactive adjustments as an outcome of NS-NNS negotiated interaction. Language Learning, 38, 45-73. http://dx.doi.org/10.1111/j.1467-1770.1988.tb00401.x

Rahimi, M., \& Sobhani, A. (2015). Teachers' different types of feedback on Iranian EFL learners' speaking errors and their impact on the students' uptake of the correct forms. Research Papers in Language Teaching and Learning, 6(1).

Rezaei, S., \& Derakhshan, A. (2011). Investigating Recast and Metalinguistic feedback in Task-based Grammar Instruction. Journal of Language Teaching and Research, 2(3). http://dx.doi.org/10.4304/j1tr.2.3.655-663

Ruili, C. (2011). Effects of Teacher's Corrective Feedback on Accuracy in the Oral English of English-Majors College Students. Theory and Practice in Language Studies, 1(5), 454-459.

Soleimani, P. (2014). The effect of explicit and implicit correction feedback on Iranian EFL learners' phonological errors. International Journal of Language Learning and Applied Linguistics World, 7(3), 543-561.

Surakka, K. (2007). Corrective feedback and learner uptake in an EFL classroom. Published masteral thesis, University of Jyväskylä, Finland.

Swain, M. (1995). Three functions or output in second SLA learning. In G. Cook \& B. Seidhofer (Eds.), 
Principle and Practice in Applied Linguistics (pp. 125-144). Oxford: Oxford University Press.

Tomczyk, E. (2013). Perceptions of Oral Errors and Their Corrective Feedback: Teachers vs. Students. Journal of Language Teaching and Research, 4(5), 924-931. http://dx.doi.org/10.4304/j1tr.4.5.924-931

Towell, R., Hawkins, R., \& Bazergui, N. (1996). The development of fluency in advanced learners of French. Applied Linguistics, 17, 84-119. http://dx.doi.org/10.1093/applin/17.1.84

Zhengwei, Q. (2013). Effects of Corrective Feedback on the Acquisition of Chinese Directional Verb Compounds by Second Language Learners. US-China Foreign Language, 11(1), 46-57.

Zhuo, C. (2010). Explicit Recast, Implicit Recast and the Acquisition of English Noun Plural: A Comparative Study. Chinese Journal of Applied Linguistics, 33(6), 55-70.

\section{Copyrights}

Copyright for this article is retained by the author(s), with first publication rights granted to the journal.

This is an open-access article distributed under the terms and conditions of the Creative Commons Attribution license (http://creativecommons.org/licenses/by/4.0/). 